doctors into sending the "patients" in the direction they want to go or keeping them the way they are.

The ethics of such behaviour is not only a medical problem but a moral issue, with economic implications of some magnitude. Study and definition are certainly needed to clarify terms of reference.-We are, etc.,

$$
\text { L. J. F. WARnANTS. }
$$

Psychiatric Department

$$
\text { D. H. Marjot. }
$$
c/o G.P.O., Singapore.

\section{Mongolian Spots}

SIR,-For the sake of the completeness of the record an addition which should be made to Dr. D. B. Jelliffe's list (21 November, p. 1330) of races in which some neonates exhibit "Mongolian spots" is that of the Eskimos. I have frequently seen them on young Eskimo infants in Labrador, and I have no doubt they are also found in the other Eskimo communities.

As Dr. Jelliffe implies, they are of neither clinical nor ethnological significance.-I am, etc.,

Edinburgh 12.

JACK CORMack.

\section{Accidents in Coal Mines}

SIR,-On the morning on which your issue was published containing comment on Accidents in Coal Mines (5 December, p. 1411), I was attending a conference of management and union representatives called to discuss safety, and subsequently widely reported in the local press. We, working in the mining industry, would agree that it is more profitable to study working conditions; accidents, we believe, are caused, they do not just happen.

What does not emerge from your comment is the considerable problems which have arisen as a result of the technical revolution which has taken place in mining in a decade. There has been no lack of awareness among mining and safety engineers, but, as your article indicates, the problems are subtle and not always capable of easy definition.-I am, etc.,

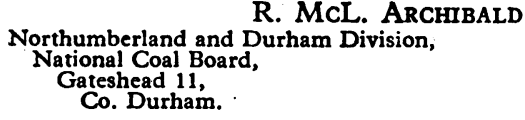

\section{Sugar and Dental Caries}

SIR,-I should like to attempt an answer to the question raised by Dr. H. Maitland Moir (5 December, p. 1463) on the relationship of breast and artificial feeding to dental caries. Whilst there is little evidence to suggest a positive relationship between breast feeding and subsequent immunity to dental decay there is an increasing awareness in the relationship of this disease to prolonged bottle feeding. ${ }^{2}$ In a recent study I have conducted into this problem (to be published) a highly positive relationship has been shown between decay in the deciduous dentition and the use of feeding bottles given to comfort children over prolonged periods of time. I was surprised to find that in a control group of pre-school children $57 \%$ had been given comforter bottles up to an average age of 1 year 11 months. Most of these bottles con- tained fresh cow's milk, but even more significant was the fact that $91 \%$ had been sweetened by the addition of sugar (sucrose).

Although these studies have only demonstrated a relationship between the prolonged use of sugared comforters and dental decay in the deciduous dentition, nevertheless a highly positive correlation has been shown between caries susceptibility in the deciduous and permanent dentition, ${ }^{3}$ thus suggesting that the prolonged use of sweetened comforter bottles in infancy and early childhood may predetermine the caries potential for many years.

In view of the significance given by Professor John Yudkin (5 December, p. 1458) to the present high consumption of sugar in this country, dental caries may be only one aspect of the problem created by the sweetened comforter bottle.-I am, etc.,

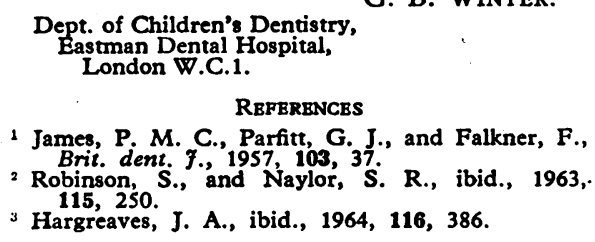
Eastman Dental Hon W.C.1. REPERENCES

1 James, P. M. C., Parfitt, G. J., and Falkner, F., Robit. dent. F., 1957 , 103, 37. .' R., ibid., 1963, $115,250$.
Hargreaves, J. A., ibid., 1964, 116, 386. G. B. WINTER.

\section{Infant Feeding}

SIR,-Dr. F. P. Hudson's letter (17 October, p. 1011) on Liga low-protein biscuits has prompted me to draw attention to two more Liga products which have a useful place in infant formulas owing to their composition and digestibility.

The "Liga three-way infant food" biscuits have been fed to healthy infants and prematures, and to infants recovering from feeding breakdowns. When added crushed in a $5-10 \%$ concentration to the appropriate milk mixture they provide a well-balanced diet up to 6 months of age. They appeal to the infants' taste and their smooth mixing quality allows concentrated bottle-feeding without blockage of the teat. To older babies the biscuit can be offered either as a snack or mixed with fruit or vegetable pulp.

The other product "Liga gluten-free" biscuits proved a well-tolerated nutrient in the treatment of coeliac disease during the crisis and later in place of gluten-free bread or other farinaceous food a valuable amplification of the reparation and maintenance diet. The difficult coeliac patient takes these biscuits well for long periods. His nutritional requirements seem adequately supplemented, as shown by the speed of recovery and the absence of relapses. - I am, etc., West Middlesex Hospital,
Isleworth, Middlesex.

$$
\text { M. DynsRi-KLein. }
$$

\section{Thyroid Nodules and Cancer}

SIR,-We read with interest but some disappointment your leading article (24 October, p. 1022). We were especially surprised to see therein no mention of the importance of directional scanning of thyroid glands in which single nodules are palpable. One of us $^{1}$ described the results of this process in a Hunterian Lecture in 1956. Of 109 " cold" nodules, $20 \%$ were definitely malignant and a further $6 \%$ possibly so; whereas of 54 " hot" and "neutral" nodules removed, none was malignant. Later ${ }^{2}$ a malignant "neutral " nodule was seen and others have reported three malignant hot nodules. ${ }^{3-5}$ This series has since become much larger but our early conclusions have not been upset by subsequent experience. If one neglects the investigation by means of radioactive iodine the overall percentage of single nodules found to be malignant was $13 \%$, twice the figure of $6.6 \%$ quoted by Veith et al. On the contrary, the incidence of cancer in multinodular glands has been found to be $8 \%$, compared with the $13.3 \%$ found by Veith et al.

Your leader lays stress on the importance of sex. The ratio of female to male patients in thyroid disorder is about $8: 1$. In thyroid carcinoma the ratio falls to $5: 1^{7}$ or even to $2: 1 .^{8}$ We therefore agree that suspicion of malignancy should be more easily aroused when the patient is a male.

We are less surely in agreement with you in the matter of age. In saying that " in women under 40 years single thyroid nodules should be removed surgically without delay" you neglect the question of whether they are " hot" or "cold" and the frequency of harmless nodularity in puberal goitres. In respiting women over the age of 40 unless the increase in size is unequivocal you seem to neglect the higher incidence of undifferentiated carcinoma in the old.

We have dealt with 150 cases of thyroid cancer in the last 10 years. Our conclusions are that cold single nodules should be removed immediately (because of the great risk of malignancy); that hot and neutral single nodules should be treated with thyroxine and removed if they do not get smaller in six months (because we have seen one malignant neutral nodule); that non-toxic multinodular goitres need only be removed if they are enlarging or causing pain or signs or symptoms of pressure despite treatment with thyroxine, undergoing a change in consistency, or in any way producing signs or symptoms suggestive of malignancy.-We are, etc.,

\section{RAYMOND GREENE.}

\section{New End Hospital, J. E. Pirrcy. \\ London N.W.3. W. SINGER.}

\section{REFBRENCBS}

I Greene, R., Ann. roy. Coll. Surg., 1957, 21, 73. Farran, H. E. A. 221 .

Med , $1956,255,65$, s Attie, J.' N., Surgery, 1960, 47, 611.

- Veith. F. Brooks, R. Grigsby, W P.

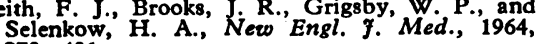

7 Piercy, J31. $\mathrm{E}$. . Postgrad. med. J., 1957, 33, 346. 1962. Blackwell, Oxford.

\section{Local Analgesics}

SIR,-In an article " To-day's Drugs" (28 November, p. 1380) it is suggested that as yet no local anaesthetic drug superior to lignocaine has appeared. I appreciate that in a review of this brevity the writer cannot cover all the advantages and disadvantages of the numerous drugs that are now available, but I am sorry to see he dismisses prilocaine so lightly.

There is no doubt that some drugs-for instance, procaine-have a special effectiveness in conduction or infiltration anaesthesia and yet little action as a topical agent. I believe that prilocaine has an action superior to lignocaine as far as the tracheobroncho tree is concerned. We have a busy endoscopy clinic in my, hospital, in which a minimum of 